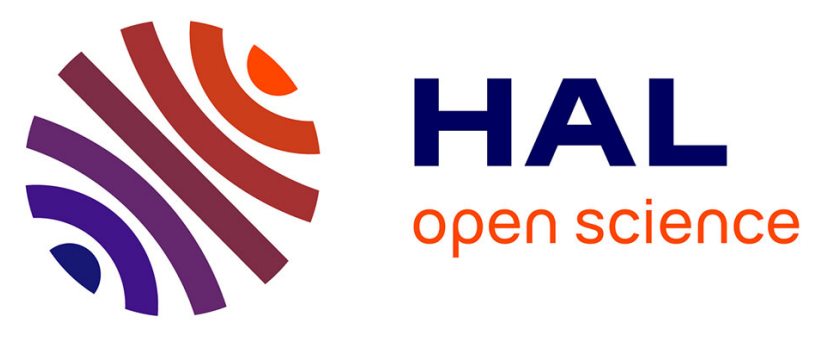

\title{
Affinity of Glycan-Modified Nanodiamonds towards Lectins and Uropathogenic Escherichia Coli
}

\author{
Volodymyr Turcheniuk, Kostiantyn Turcheniuk, Julie Bouckaert, Alexandre \\ Barras, Tetiana Dumych, Rostyslav Bilyy, Vladimir Zaitsev, Aloysius \\ Siriwardena, Qi Wang, Rabah Boukherroub, et al.
}

\section{To cite this version:}

Volodymyr Turcheniuk, Kostiantyn Turcheniuk, Julie Bouckaert, Alexandre Barras, Tetiana Dumych, et al.. Affinity of Glycan-Modified Nanodiamonds towards Lectins and Uropathogenic Escherichia Coli. ChemNanoMat, 2016, 2 (4), pp.307-314. 10.1002/cnma.201500229 . hal-01679652

\section{HAL Id: hal-01679652 https://hal.science/hal-01679652}

Submitted on 10 Jan 2018

HAL is a multi-disciplinary open access archive for the deposit and dissemination of scientific research documents, whether they are published or not. The documents may come from teaching and research institutions in France or abroad, or from public or private research centers.
L'archive ouverte pluridisciplinaire HAL, est destinée au dépôt et à la diffusion de documents scientifiques de niveau recherche, publiés ou non, émanant des établissements d'enseignement et de recherche français ou étrangers, des laboratoires publics ou privés. 


\title{
Affinity of Glycan-Modified Nanodiamonds towards Lectins and Uropathogenic Escherichia Coli
}

\author{
Authors: \\ Volodymyr Turcheniuk, Dr Kostiantyn Turcheniuk, Dr Julie Bouckaert, Alexandre Barras, Dr \\ Tetiana Dumych, Dr Rostyslav Bilyy, Prof. Vladimir Zaitsev, Dr. Aloysius Siriwardena, Dr. Qi \\ Wang, Dr. Rabah Boukherroub, and Prof. Sabine Szunerits
}

First published: 24 February 2016

DOI: $\underline{10.1002 / \mathrm{cnma} .201500229}$

\begin{abstract}
Nanodiamond particles (NDs) modified with glycan ligands are revealing themselves to have great promise as new nanomaterials for combating biofilm formation and as promising anti-adhesive scaffolds. Currently, the strategies at hand to formulate glycan-modified NDs (glyco-NDs) are limited to a few reports. We demonstrate herein that the photoinduced covalent attachment of unmodified sugars results in glyco-NDs with high binding affinity to lectins and a uropathogenic Escherichia coli strain (E. coli UTI89). While the binding affinities of glycoNDs to different lectins is partially sacrificed when monosaccharides such as mannose are photochemically integrated onto NDs, in the case of disaccharides and oligosaccharides the binding affinity of glyco-NDs to lectins is preserved. Moreover, mannan-modified NDs show strong interactions with uropathogenic E. coli., suggesting the effectiveness of photochemically formed glyco-NDs for disruption of E. coli-mediated biofilms.
\end{abstract}

\section{Introduction}

The design and preparation of sugar-coated nanoparticles and their applications as polyvalent tools to study and intervene in carbohydrate-mediated interactions have received sustained attention over the past years.[1-6] Carbohydrates are very important components of living organisms and have been identified to play a central role in a large panel of biological processes such as cell-cell communication, viral and bacterial infection, and inflammation and immune responses. The extremely low affinity of carbohydrates, typically in the milli- to micromolar range [mm- $\mu \mathrm{m}],[7]$ to biological objects is compensated for by nature using clustering effects resulting in higher affinities towards the glycan targets. This cooperative multivalent interaction is significantly stronger than the corresponding monovalent one, resulting in nanomolar [nM] affinities and high selectivities. Next to the design of highaffinity glycan ligands, $[\underline{3,8-10}]$ the integration of carbohydrates onto nanometric scaffolds has become a well-accepted strategy to mimic glycan-clustering effects of nature and to provide a surface with multivalent carbohydrate presentation. 
One of the first types of multivalent nanoscaffolds developed and used as an adhesion inhibitor is gold glycoconjugates.[3,11] Next to gold, carbon-based nanomaterials have been investigated as glycan scaffolds as they comply well with several requirements needed such as easy and stable surface functionalization, good dispersibility in aqueous media, and broad availability.[1, 4, 6, 8, 12, 13] Next to fullerene-based glycoclusters, $[\underline{8,13,14]}$ nanodiamonds (NDs) are emerging as particularly well-suited for multivalent applications.[1, 4, 6, 12, 15] Amongst the advantages of NDs over other carbon-based materials is that they are completely inert, optically transparent, biocompatible, have the ability to emit light, and can be functionalized in many ways depending on their intended ultimate application.[16-21] Although in vivo toxicity of nanoparticles is dependent on specific surface characteristics, ND particles did not induce significant cytotoxicity in a variety of cell lines[22,23] and were used in various biomedical applications.[24-26]

Despite their evident potential for glycobiology, there are only few reports on glyconanodiamonds (glyco-NDs).[1, 4, 6, 12] Krueger and co-workers used a multistep reaction including a Diels-Alder cycloaddition of 1,2-dimethylbromide phenol to the ND surface, followed by a classical aromatic sulfonation and reduction to thiol.[4] The thiol-modified NDs were used as anchors for allyl-modified glycans in a "thiol-ene" type reaction and allowed the efficient detection and removal of pathogenic bacteria. More recently, they have shown the potential of thiourea-bridged ND glycoconjugates to inhibit bacterial adhesion.[6] We have constructed glyco-NDs through the covalent conjugation of propargyl-terminated sugar components to azide-functionalized NDs, as well as the conjugation of azide-terminated sugars to propargyl-terminated NDs.[1,27] It was demonstrated that these glyco-NDs inhibit type 1 fimbriae-mediated yeast-agglutination and human bladder-cell adherence in a sugarselective manner. The eukaryotic cell-adherence inhibitory efficiency of ND-mannose was revealed to be far superior to those reported for other glycan-modified particles and nanostructures directed against $E$. coli.

Yet, the requirement for prior derivatization of the appropriate glycan presents a significant hurdle for the construction of glyco-NDs, as the synthetic effort increases exponentially from mono- to di- and oligosaccharides. A recently developed strategy for the formation of gold glyconanoparticles involved photoinduced covalent attachment of native carbohydrates.[28, 29] The method takes advantage of the photochemistry of arylazides, which upon light activation convert to reactive nitrenes.[30] The highly reactive nitrene intermediate formed is believed to interact with glycans through $\mathrm{C}-\mathrm{H}$ and $\mathrm{N}-\mathrm{H}$ insertion reactions, creating highly robust covalent linkages. We recently compared the effectiveness of mannose-modified surfaces either formed photochemically or via $\mathrm{Cu}^{\mathrm{I}}$ "click" reactions for lectin recognition using surface plasmon resonance.[31] Although photochemical surface conjugation did not give anomeric center-specific surface attachment, this was seen not to have a bearing on lectin recognition, with preserved binding affinity and specificity.

The purpose of this work is to make the photochemical strategy available for the formation of a variety of glyco-NDs. Certainly, one drawback of the proposed photochemical approach is the nonspecificity of the coupling reaction, where the attachment of glycans to NDs does not occur exclusively via their reducing ends. It will be shown that the binding affinities of glycoNDs to lectins is partially sacrificed when monosaccharides such as mannose are linked, while with disaccharides and oligosaccharides the binding affinity of glyco-NDs to lectins is entirely preserved. 
In addition, we examined whether these glyco-NDs show affinity to a uropathogenic Escherichia coli strain (E. coli UTI89). Among the targets that have been identified for the development of anti-adhesive strategies are type-1 fimbriae, which constitute major virulence factors produced by E. coli UTI89.[32] Type-1 fimbriae are filamentous tubular structures each of $0.2-2.0 \mu \mathrm{m}$ in length and 5-7 $\mathrm{nm}$ in diameter that are distributed over the entire surface of the bacterium. The lectin located at the extremity of type-1 fimbriae, FimH, contributes to tissue colonization through its specific recognition of the terminal $\alpha$-dmannopyranosyl units present on cell-surface glycoproteins. We have recently demonstrated that mannose-modified NDs exhibit marked anti-adhesive activity for E. coli UTI89 in cellbased assays without displaying toxicity against eukaryotic cells.[1, 12] The coupling strategy used for the fabrication of these particles was based on the $\mathrm{Cu}^{\mathrm{I}}$-catalyzed Huisgen cycloaddition reaction ("click" reaction) between NDs decorated with surface azidophenyl or propargyl functions and the corresponding synthetic sugar analogue. Herein, we investigate the potential of photochemically grafted native mannose versus mannan to interact with $E$. coli UTI89 using a fluorescence-based agglutination assay.[33]

\section{Results and discussion}

\subsection{Synthesis of glyco-NDs via photoactivation of perfluorophenylazide-modified NDs}

We have recently shown that dopamine, known to have strong interactions with different metal oxides and graphene-like structures, is a viable agent for the functionalization of nanodiamonds.[16, 27] A dopamine derivative of perfluorophenylazide (1) was therefore synthesized through reaction of the $\mathrm{N}$-succinimidyl 4-azidotetrafluorobenzoate with the amine groups of dopamine (Figure $1 \mathrm{~A})$. Hydroxylated nanodiamonds (ND-OH) were subsequently functionalized with ligand (1) (Figure $1 \mathrm{~B}$ ). The functionalized ND particles (ND-PFPA) were characterized by Fourier transform infrared (FTIR) spectroscopy (Figure 2 A) and X-ray photoelectron spectroscopy (XPS) (Figure 2 B).

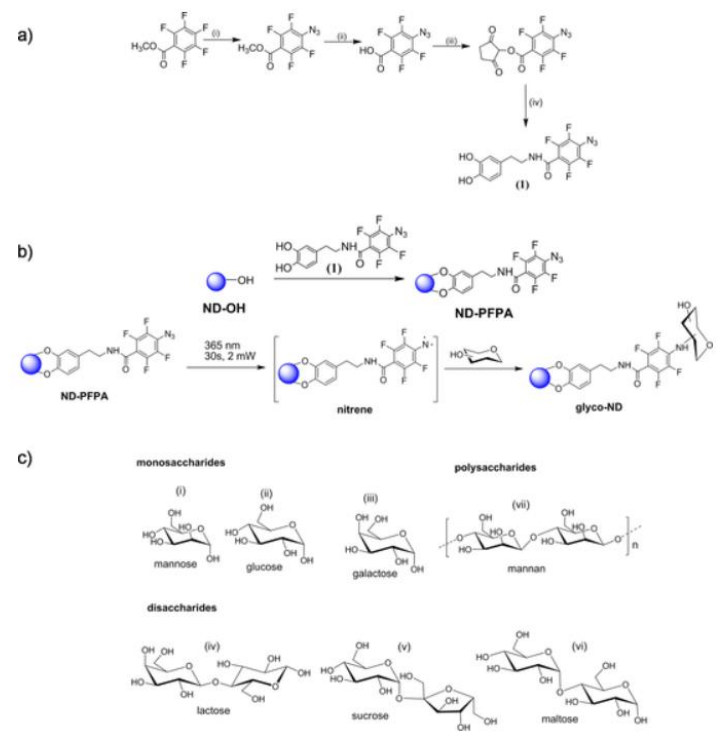

Figure 1. 
a) Synthesis of perfluorophenyl azide (PFPA)-modified dopamine (1): (i) $\mathrm{NaN}_{3}$, acetone/water, $90^{\circ} \mathrm{C}, 2 \mathrm{~h}, 85 \%$; (ii) $\mathrm{NaOH}$, water, $3 \mathrm{~h}$, RT, $90 \%$, (iii) NHS, DCM, RT, overnight; $95 \%$, (iv) dopamine hydrochloride, TEA, DMF, RT, argon, $91.4 \%$. b) Modification of ND-OH with ligand (1) forming NDPFPA. c) Formation of glyco-NDs through the photochemical linking of mono-, di-, and a polysaccharide onto NDs.

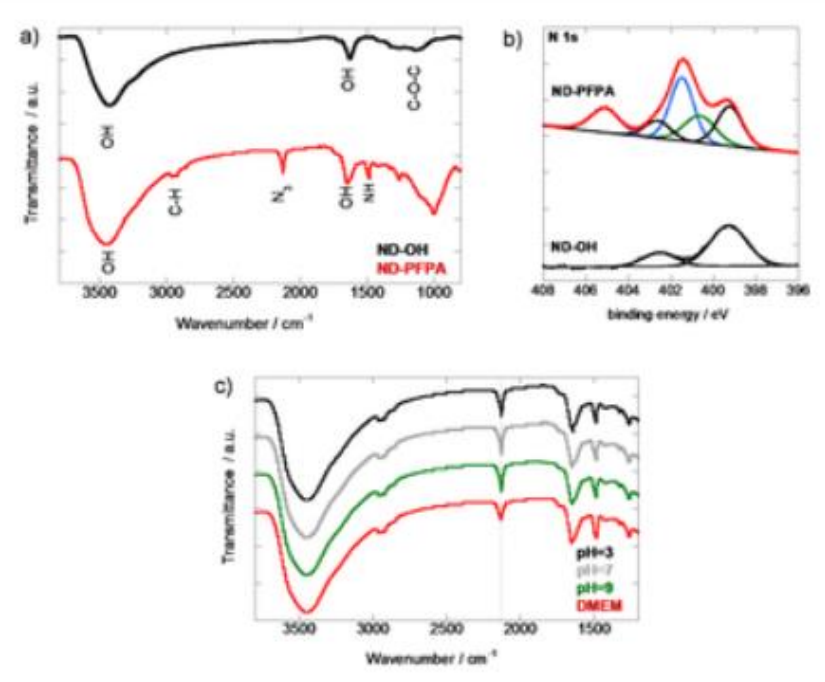

Figure 2.

a) FTIR spectra of ND-OH (black) and ND-PFPA (red). b) N 1s highresolution XPS spectra of ND-OH (black) and ND-PFPA (red). c) FTIR spectra of ND-PFPA after immersion for $24 \mathrm{~h}$ in $\mathrm{pH} 3, \mathrm{pH} \mathrm{7,} \mathrm{pH} 9$, and DMEM.

The FTIR spectrum of the as-received ND-OH (Figure 2 A) shows a broad peak at $3447 \mathrm{~cm}^{-1}$ assigned to the vibration of surface hydroxyl groups or/and adsorbed water molecules, and an additional sharper one at $1633 \mathrm{~cm}^{-1}$ due to the bending mode $\delta_{(\mathrm{OH})}$ of surface hydroxyl groups on the NDs. In addition, the band at $1107 \mathrm{~cm}^{-1}$ is indicative of the presence of $\mathrm{C}-\mathrm{O}-\mathrm{C}-$ functional groups of cyclic ethers. After reaction of $\mathrm{ND}-\mathrm{OH}$ particles with ligand (1) a new vibration peak at $2125 \mathrm{~cm}^{-1}$ characteristic of the $v_{\mathrm{as}(\mathrm{N} 3)}$ stretching appears. The $\mathrm{C}-\mathrm{H}$ stretching vibration modes are detected at $2850-2970 \mathrm{~cm}^{-1}$ and are partially masked by the large band at $3447 \mathrm{~cm}^{-1}$. The ND-PFPA particles display in addition a band at $2125 \mathrm{~cm}^{-1}$ characteristic of the $v_{\mathrm{as}(\mathrm{N} 3)}$ stretching mode and a band at $2936 \mathrm{~cm}^{-1}$ characteristic of the presence of $\mathrm{C}-\mathrm{H}$ bonds, as reported previously.[16] The band at $1546 \mathrm{~cm}^{-1}$ is most likely associated with the $-\mathrm{NH}-\mathrm{C}=\mathrm{O}$ bond present in ligand (1).

The presence of the azide group on ND-PFPA is in addition confirmed by the $\mathrm{N} 1 \mathrm{~s}$ high resolution XPS spectrum (Figure 2 B). Bands at $405.2\left(\mathrm{Ar}-\mathrm{N}=N^{+}=\mathrm{N}^{-}\right)$and $401.9 \mathrm{eV}$ $\left(\mathrm{Ar}-N=\mathrm{N}^{+}=N^{-}\right)$, characteristic for the $-\mathrm{N}_{3}$ groups, are observed. The contribution of the $-N \mathrm{H}-\mathrm{C}=\mathrm{O}$ linkage is seen at $400.6 \mathrm{eV}$. Bands at 402.7 and $399.2 \mathrm{eV}$ are also observed in the initial ND-OH. These correspond most likely to nitrogen functions such as $\mathrm{N}-\mathrm{O}$ and $\mathrm{C}-\mathrm{N}$ most likely generated during the detonation process of trinitrotoluene with formation of NDs. As seen in Table $\underline{1}$, the nitrogen content accounts for 1.5 at $\%$ and might be responsible for the 4

DOI: 10.1002/cnma.201500229 - Journal: ChemNanoMa- Post-print 
positive surface potential of ND-OH (Table 1), as also reported by others. The level of $\mathrm{N} 1 \mathrm{~s}$ is increased in ND-PFPA particles to 8.4 at \% with a $\mathrm{F} /(\mathrm{N}-1.5)$ ratio of 1.28 , close to the theoretical value of 1.33 .

Table 1. Physical properties of the NDs modified with ligands (1).

\begin{tabular}{|l|c|c|c|c|c|}
\hline NDs & Diameter [nm] & PDI ${ }^{[a]}$ & Zeta potential $[\mathrm{mV}]$ & $\mathrm{N}^{[\mathrm{b}]}[\%]$ & $\mathrm{F}^{[\mathrm{b}]}[\%]$ \\
\hline ND-OH & $79 \pm 13$ & $0.246 \pm 0.002$ & $35 \pm 2$ & 1.5 & 0.0 \\
ND-PFPA & $126 \pm 3$ & $0.168 \pm 0.021$ & $34 \pm 2$ & 8.4 & 6.9 \\
\hline
\end{tabular}

To ensure the stability of the conjugates and that the dopamine ligand does not detach over time, ND-PFPA particles were immersed for $24 \mathrm{~h}$ at different $\mathrm{pH}(3,7$, and 9) as well as in biological medium such as Dulbecco's modified Eagle medium (DMEM) and the FTIR spectra were recorded. As seen from Figure $2 \mathrm{C}$, no significant decrease of the $v_{\mathrm{as}(\mathrm{N} 3)}$ band at $2125 \mathrm{~cm}^{-1}$ is observed upon immersion into solutions of different $\mathrm{pH}$, and only a slight decrease was observed when incubated in biological medium. The ether bond between the diamond surface and the aromatic ring of dopamine seems to be rather stable and comparable of those on organic molecules with no hydrolysis taking place at this timeframe.

Photochemical linkage of glycans to NDs takes advantage of the photochemistry of arylazides, which upon light activation convert to reactive nitrenes (Figure $1 \mathrm{C}$ ). The highly reactive nitrenes can interact directly with any glycan through $\mathrm{C}-\mathrm{H}$ and/or $\mathrm{N}-\mathrm{H}$ insertion reactions, creating highly robust covalent linkage. Mono-, di- and a polysaccharide were photochemically integrated onto ND-PFPA particles (Figure 1 C) by mixing a solution of ND-PFPA in acetonitrile with aqueous solutions of the respective glycan, and irradiating the mixtures at 365 $\mathrm{nm}$ for $30 \mathrm{~s}$ at $2 \mathrm{~mW}$. Representative FTIR spectrum of mannose and mannan-modified NDs are shown in Figure $3 \mathrm{~B}$ and show the complete disappearance of the characteristic $-\mathrm{N} 3$ vibration band at $2128 \mathrm{~cm}^{-1}$, suggesting that all the azido groups were consumed in the photochemical process. The band at $1633 \mathrm{~cm}-1$ due to the bending mode $\delta(\mathrm{OH})$ increased significantly in the case of ND-mannan. The N 1s XPS spectra after photochemical linking of mannose also changed significantly. The conversion of the azide group into $\mathrm{C}-\mathrm{N}$ bonds is evidenced by the disappearance of the bands at $405.2(\mathrm{Ar}-\mathrm{N}=\mathrm{N}+=\mathrm{N}-$ ) and $401.9 \mathrm{eV}$ $(\mathrm{Ar}-\mathrm{N}=\mathrm{N}+=\mathrm{N}-)$ and the appearance of a band at $400.6 \mathrm{eV}$ due to the formation of $\mathrm{C}-\mathrm{N}$ bonds. The presence of $\mathrm{F} 1 \mathrm{~s}$ signal at $686 \mathrm{eV}$ is an additional indication of the formation of NDmannose (Figure $3 \mathrm{C}$ ). To validate further the covalent linking of the glycan to ND-PFDA, a solution of ND-PFPA in acetonitrile was mixed with an aqueous solution of mannan and left for $24 \mathrm{~h}$. The characteristic $-\mathrm{N} 3$ vibration band at $2128 \mathrm{~cm}-1$ was still present on ND-PFPA confirming the interaction of the glycan with the dopamine ligand on the NDs. 


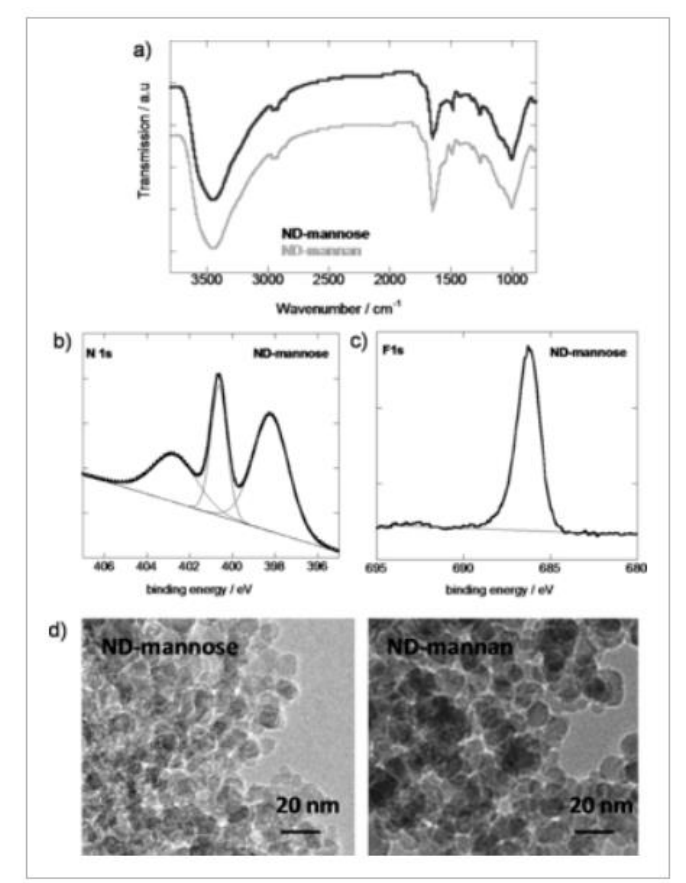

Figure 3.

a) FTIR spectra of ND-mannose (black) and ND-mannan (grey); b) N 1s spectrum of ND-mannose; c) F 1s spectrum of ND-mannose; d) TEM images of ND-mannose and ND-mannan.

Representative transmission electron microscopy (TEM) images of ND-mannose and NDmannan (Figure $\underline{3}$ D) reveal the presence of spherical particles with a mean diameter of $24 \pm 8$ $\mathrm{nm}$ for all structures independent of the glycan present on their surface.

The amount of glycan integrated onto ND-PFPA was analyzed using the well-established phenol-sulfuric acid assay and proved to be glycan dependent (Table 2). In the case of mannose, the sugar loading is comparable to mannose-ND formed via "click" chemistry as reported previously by us.[1] In the case of disaccharide-modified NDs, the amount of incorporated saccharides is about twice that of mannose, with the highest sugar loading observed for mannan-NDs.

Table 2. Physical properties of different glycan-NDs. 


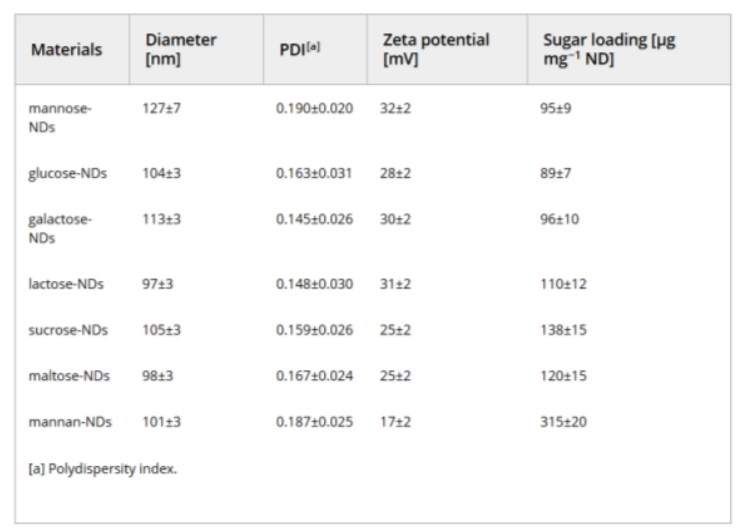

\subsection{Lectin binding assays}

The glyco-NDs were subjected to affinity binding studies with a series of fluorescently labeled lectins (Figure 4). FITC-labeled Concanavalin A from Canavalia ensiformis (Con A) and FTIR-labeled Lens culinaris (LENS) are primarily selective towards to mannopyranoside and were used as positive controls. The $\alpha$-d-galactopyranose specific Arachis hypogaea (PNA) was used as negative control for mannose-, glucose-, sucrose-, maltose-, and mannan-modified ND particles, while Con A and LENS were negative controls for galactose-modified NDs. LactoseNDs are expected to interact with all lectins as this disaccharide is derived from the condensation of galactose and glucose-forming $\beta(1 \rightarrow 4)$ glycosidic linkage. The fluorescence intensities recorded after interaction of glyco-NDs solutions for $30 \mathrm{~min}$ with different lectins confirm that the binding affinities of the photolinked sugars are in accordance with the expected binding characteristics for each lectin. Mannose-modified NDs exhibit several times larger fluorescence signals when incubated with Con A and LENS than with PNA due to the higher binding affinity. The fluorescence intensity recorded for mannose-NDs in the presence of FITClabeled PNA is of the same magnitude than that measured using ND- $\mathrm{OH}$. This fluorescence level is thus most likely linked to nonspecific interaction of the protein with the particle surface. Galactose-modified NDs show the opposite behavior, strong fluorescence upon incubation with PNA and weak with Con A and LENS lectins. In the case of glucose-NDs, the fluorescence signal upon incubation is strongest for LENS, lower for Con A, and weak for PNA. The tetrameric lectin Con A has next to mannose a reported binding site specific to glucose, with however a lesser extent. The lowered fluorescence signal upon incubation of glucose-ND with Con A when compared to glucose-ND specific LENS correlates to this difference in affinity.

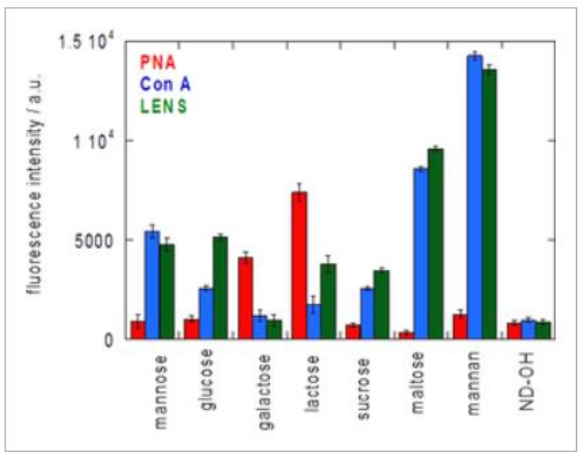

\section{Figure 4.}


Fluorescence intensities evaluated using FTIC-labeled lectins after reaction with glycan-terminated NDs in a 1/1 ratio $\left(1 \mathrm{mg} \mathrm{mL}^{-1}\right)$ in tris buffer solution (pH 7.4 containing $\mathrm{Mg}^{2+}, \mathrm{Ca}^{2+}, \mathrm{NaCl}$ ): Fluorescent measurements were performed using an excitation wavelength of $485 \mathrm{~nm}$ and an emission wavelength of $520 \mathrm{~nm}$; the results are derived from the data of 4 independent experiments.

To further investigate the generality of this coupling method and the specificity to surfacebound glycans, disaccharide, polysaccharide, and mannan were each photochemically linked to ND-PFPA and their affinity towards the three lectins was determined. The interaction of lactose-NDs with PNA or LENS resulted in about twice the fluorescence signal for PNA. This disaccharide seems to be preferentially coupled to the NDs via its glucose end. In the case of sucrose-NDS, a disaccharide composed of glucose and fructose, no interaction with PNA was observed, while the interaction with glucose-specific Con A and LENS was higher, suggesting that some of the sucrose is linked via the fructose end to ND-PFPA. Using maltose-ND, a disaccharide formed from two units of glucose with an $\alpha(1 \rightarrow 4)$ bond, strong binding to Con A and LENS were observed, being stronger than that obtained with mannose.

The strongest interaction with Con A and LENS is observed with mannan-modified NDs. These particles showed a three times higher sugar loading than mannose-NDs, which correlates to an approximately three times larger fluorescent signal.

\subsection{Effect of mannose-NDs and mannan-NDs on agglutination of $E$. coli UTI89 strains}

\section{Fluorescence-based agglutination assay in the presence of mannose and mannose-NDs}

Next, we examined whether mannose-NDs and mannan-NDs show affinity to uropathogenic $E$. coli UTI89. As discussed in the introduction, FimH, a lectin located at the extremity of type 1 fimbriae, is a major virulence factor produced by E. coli UTI89, and contributes to tissue colonization through its specific recognition of the terminal $\alpha$-d-mannopyranosyl units present on cell-surface glycoproteins. Interfering with this interaction has been recently shown to be possible with mannose-modified NDs formed by "click" chemistry of propargyl and/or azidemodified mannose derivatives. $[1,12]$ To scrutinize the potential of the photochemically formed mannose-NDs, we investigated if such particles display enhanced agglutination effects towards E. coli UTI89 when compared to free mannose in solution. A fluorescence-based agglutination assay was used for this purpose.[33] It is based on mixing different concentrations of mannose and mannose-NDs with fluorescently labeled E. coli UTI89 formed through genetic modification to express turboFP635 (Katushka) fluorescent proteins, emitting at $635 \mathrm{~nm}$ (upon excitation at $580 \mathrm{~nm}$ ).[34] Figure $\underline{5}$ depicts diverse fluorescence images of Katushka expressing E. coli after interaction for $4 \mathrm{~h}$ at $4{ }^{\circ} \mathrm{C}$ with different concentrations of mannose-NDs (1-300 $\left.\mu \mathrm{g} \mathrm{mL} \mathrm{m}^{-1}\right)$. As a control, the influence of $\mathrm{ND}-\mathrm{OH}$ and mannose in solution were investigated. These agglutination tests show that mannose, as expected, gives no E. coli UTI89 agglutination in the concentration range tested. In contrast to free mannose in solution, mannose-NDs display a concentration dependent agglutination behavior at a minimal concentration of $\approx 50 \mu \mathrm{g} \mathrm{mL}^{-1}$. 


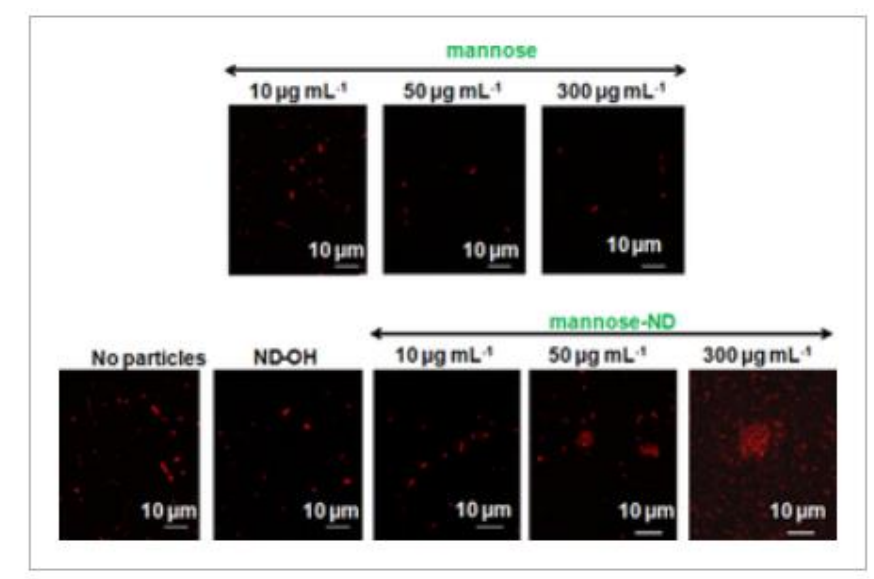

\section{Figure 5.}

Fluorescence-based agglutination assay for: Fluorescence images of Turbo FP635 (Katushka protein) expressing E. coli UTI89 $\left(1 \times 10^{8} \mathrm{cfu} \mathrm{ml}^{-1}\right)$ in the presence of different concentrations of mannose, in the absence of particles (no particles) and in the presence of ND-OH $\left(100 \mu \mathrm{g} \mathrm{mL}^{-1}\right)$ and different mannose-NDs (the values correspond to total mannose concentration in the solution and is directly comparable with the results of free mannose).

\section{Fluorescence-based agglutination assay in the presence of mannan and mannan-NDs}

In addition, the agglutination behavior of mannan and mannan-NDs was investigated in a comparable manner. Mannan is a cell-wall component of microorganisms, consisting of dmannose residues expanded by $\alpha-(1 \rightarrow 6)-, \alpha-(1 \rightarrow 3)-, \alpha-(1 \rightarrow 2)-$ linkages. Park and co-workers reported on the formation of carboxylic mannan-coated iron oxide nanoparticles to target antigen-presenting cells (APCs), including macrophages, by the specific interaction between the mannose ligand and the mannose receptors on APCs.[35] The choice of mannan as the integral component in NDs is to take advantage of the expected high binding affinity towards E. coli UTI89 due to the presence of multiple mannose ligands in this polysaccharide. Figure $\underline{6}$ exhibits the results of mannan and mannan-NDs addition to a solution of E. coli UTI89. In contrast to mannose only (Figure 5), addition of $100 \mu \mathrm{g} \mathrm{mL}^{-1}$ mannan reveals partial E. coli UTI89 agglutination. Moreover, mannan-ND particles have an ability to agglutinate $E$. coli with an onset at concentrations as low as $\approx 10 \mu \mathrm{g} \mathrm{mL}^{-1}$. This is in line with the believed multivalent presentation of mannan on nanoparticles.

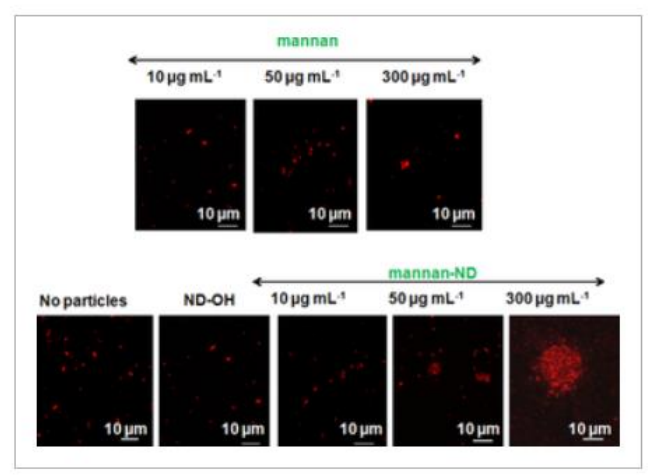




\section{Figure 6.}

Fluorescence-based agglutination assay for: Fluorescence images of Turbo FP635 (Katushka protein) expressing E. coli UTI89 $\left(1 \times 10^{8} \mathrm{cfu} \mathrm{m}^{-1}\right)$ in the presence of different concentrations of mannan, in the absence of particles (no particles) and in the presence of ND-OH $\left(100 \mu \mathrm{g} \mathrm{mL}^{-1}\right)$ and different mannan-NDs (the values correspond to total mannan concentration in the solution and is directly comparable with the results of free mannan).

\section{Conclusions}

In conclusion, we have shown that photochemical linking of unmodified mono-, di-, and polysaccharides to nanodiamond particles pre-modified with perfluorophenylazide ligands is a general method for coupling underivatized carbohydrates to diamond nanostructures. The coupling method, based on photochemically induced $\mathrm{CH}$ insertion is fast and gives a high coupling yield. More importantly, the resulting glyco-NDs maintained their expected binding affinity and specificity towards their partner lectins. These results confirm previous reports on the effectiveness of photochemically formed glycan surfaces to selectively interact with specific lectins. The generality of photochemical approach to provide glyco-NDS was in addition demonstrated through the formation of various disaccharide and a polysaccharide modified NDs. It should be noted, however, that in the case of disaccharide-modified NDS, lactose preferentially couples via the glucose end to NDs, while in the case of sucrose, the fructose end preferential bind photochemically. The reasons for this behavior are currently not understood. "Click" chemistry approaches show a higher degree of control for anchoring disaccharides onto particles. However, this limitation is absent in polysaccharides such as mannan and the approach is believed to be mainly adapted for such glycans. That was the primary motivation for investigating the potential of mannan-NDs to interact with E. coli UTI89. Through a fluorescence-based agglutination assay, we showed that mannan-NDs display E. coli agglutination at concentrations of $\approx 10 \mu \mathrm{g} \mathrm{mL}^{-1}$, which is much lower than that for free mannan and mannose-NDs. Taken together, the findings presented here show that the nanostructures described should be further developed and evaluated as potential anti-adhesives for countering bacterial colonization and infections in vivo.

\section{Experimental Section}

\subsection{Materials}

Hydroxyl-terminated nanodiamonds (ND-OH) were purchased from International Technology Center (Raleigh, NC, USA).

All chemicals were of reagent grade or higher and were used as received unless otherwise specified. Methyl pentafluorobenzoate, sodium azide $\left(\mathrm{NaN}_{3}\right)$, dimethylformamide (DMF), diethyl ether, magnesium sulfate $\left(\mathrm{MgSO}_{4}\right)$, acetone, methanol $(\mathrm{MeOH})$, dichloromethane (DCM), sodium hydroxide $(\mathrm{NaOH})$, hydrochloric acid $(\mathrm{HCl}), N, N^{\prime}$-dicyclohexylcarbodiimide (DCC), 4-dimethylaminopyridine (DMAP), copper(II) sulfate pentahydrate $\left(\mathrm{CuSO}_{4} \cdot 5 \mathrm{H}_{2} \mathrm{O}\right)$, $1-$ ascorbic acid, ethylenediaminetetraacetic acid (EDTA), mannose, glucose, galactose, lactose, sucrose, maltose, mannan (from Saccharomyces cerevisia), FITC-labeled Concanavalin A (from Canavalia ensiformis), FITC-labeled Lens culinaris (LENS) and FITC-labeled Arachis 
hypogaea (PNA) were obtained from Sigma-Aldrich and used without further purification. Azido benzoic acid was purchased from TCI Europe (Belgium). Ultrapure water (Milli-Q, 18 $\mathrm{M} \Omega \mathrm{cm}$ ) was used for the preparation of the solutions and for all rinsing steps. Dulbecco's modified Eagle medium (DMEM) was obtained from Gibco by Life Technologies.

\subsection{Synthesis of 4-azido- $N$-(3,4-dihydroxyphenethyl)-2,3,5,6-tetrafluorobenzamide (1)}

\subsection{1 -Azidotetrafluorobenzoic acid}

Pentafluorobenzoic acid methyl ester (PFPA, $300 \mathrm{mg}, 1.3 \mathrm{mmol}$ ), $\mathrm{NaN}_{3}$ (129 mg, $2 \mathrm{mmol}$ ) were mixed in acetone/water in 2/1 ratio. The mixture was refluxed for $3 \mathrm{~h}$. Afterwards, it was evaporated under reduced pressure and water was added. The precipitate was washed with water several times and dried. Then it was dissolved in $10 \% \mathrm{NaOH}$ water/methanol solution and stirred for $4 \mathrm{~h}$, acidified to $\mathrm{pH} 5$ and extracted using $\mathrm{CH}_{2} \mathrm{Cl}_{2}$. The organic layer was washed with water, dried and evaporated to give $270 \mathrm{mg}$ ( $86 \%$ yield) of white precipitate. ${ }^{1} \mathrm{H}$ NMR (300 MHz, DMSO): $\delta=11.3 \mathrm{ppm}(1 \mathrm{H})$. MS (ESI): $m / z(\%)=258[M+\mathrm{Na}]^{+}$.

\section{N-Succinimidyl 4-azidotetrafluorobenzoate}

A solution of 4-azidotetrafluorobenzoic acid (234 mg, $1 \mathrm{mmol}), \mathrm{N}$-hydroxysuccinimide (115 $\mathrm{mg}, 1.00 \mathrm{mmol})$, and dicyclohexylcarbodiimide $(211 \mathrm{mg}, 1.02 \mathrm{mmol})$ in DCM $(6.5 \mathrm{~mL})$ was stirred at room temperature overnight. The mixture was filtered. The filtrate was evaporated and the product was purified by column chromatography to give $317.6 \mathrm{mg}$ (95\% yield) as a colorless solid. ${ }^{1} \mathrm{H}$ NMR (300 MHz, DMSO): $\delta=2.91 \mathrm{ppm}(4 \mathrm{H}, \mathrm{s}) . \mathrm{MS}$ (ESI): $\mathrm{m} / \mathrm{z}(\%)=355$ $[M+\mathrm{Na}]^{+}$.

\subsection{2 -azido-N-(3,4-dihydroxyphenethyl)-2,3,5,6-tetrafluorobenzamide (1)}

To a solution of dopamine hydrochloride $(113.4 \mathrm{mg}, 0.6 \mathrm{mmol})$ in DMF $(4 \mathrm{~mL})$ were added TEA (108.4 mL, $0.77 \mathrm{mmol}$ ) and $N$-succinimidyl 4-azidotetrafluorobenzoate (200 $\mathrm{mg}, 0.6$ mmol). The mixture was stirred overnight at room temperature under argon. Then water was added, and the resulting precipitate was filtered and washed with water several times and then dried at $100{ }^{\circ} \mathrm{C}$ carefully to give $203 \mathrm{mg}\left(91.4 \%\right.$ yield) of white powder. ${ }^{1} \mathrm{H}$ NMR $(300 \mathrm{MHz}$, DMSO): $\delta=8.96-8.92(\mathrm{t}, 1 \mathrm{H}$, amide), $8.80(\mathrm{~s}, 1 \mathrm{H}, \mathrm{OH}), 8.74(\mathrm{~s}, 1 \mathrm{H}, \mathrm{OH}), 6.65-6.13(\mathrm{~m}, 2 \mathrm{H}$, arom) 6.49-6.46 (d, $1 \mathrm{H}$, arom), 3.42-3.36 (q, $\left.2 \mathrm{H}, \mathrm{CH}_{2} \mathrm{NHCO}\right), 2.65-2.60 \mathrm{ppm}\left(\mathrm{t}, 2 \mathrm{H}, \mathrm{CH}_{2}\right)$.

\subsection{Formation of ND-PFPA}

A suspension of ND-OH particles in anhydrous acetonitrile (10 $\mathrm{mg}$ in $5 \mathrm{~mL})$ was added to a solution of ligand (1) in acetonitrile $(10 \mathrm{mg})$ and stirred at room temperature for $24 \mathrm{~h}$. The formed ND-PFPA particles were isolated by centrifugation at $10000 \mathrm{rpm}$, purified through four consecutive wash/centrifugation cycles at $10000 \mathrm{rpm}$ with acetonitrile and ethanol, and finally oven dried at $50{ }^{\circ} \mathrm{C}$ for $24 \mathrm{~h}$.

\subsection{Photochemical linkage of glycans to ND-PFPA}

ND-PFPA (in anhydrous acetonitrile $\left(1 \mathrm{mg} \mathrm{mL}^{-1}\right.$ in $\left.200 \mu \mathrm{L}\right)$ was mixed with an aqueous solution of the respective glycans (Figure 1) $\left(1 \mathrm{mg} \mathrm{mL}^{-1}\right.$ in $\left.400 \mu \mathrm{L}\right)$ in a quartz cuvette. The 
mixture was irradiated with a UV lamp (Hamamatsu, $2 \mathrm{~mW} \mathrm{~cm}^{-2}$ ) for $30 \mathrm{~s}$ under vigorous stirring. The resulting glyco-NDs were isolated by centrifugation at $10000 \mathrm{rpm}$ for $15 \mathrm{~min}$. In order to remove excess mannose, three additional washing/centrifugation cycles at $10000 \mathrm{rpm}$ with water were performed.

\subsection{Determination of carbohydrate loading on the NDs}

A calibration curve for carbohydrate concentrations in solution was established. For this, a phenolic aqueous solution $(5 \mathrm{wt} \%, 60 \mu \mathrm{L})$ and concentrated $\mathrm{H}_{2} \mathrm{SO}_{4}(900 \mu \mathrm{L})$ was added to an aqueous carbohydrate solution $(60 \mu \mathrm{L})$, stirred for $10 \mathrm{~min}$ and then an absorption spectrum of the mixture was recorded (PerkinElmer Lambda 950 dual beam) against a blank sample (without carbohydrate). The absorbance of the solution was measured at two wavelengths: $\lambda_{1}=495$ and $\lambda_{2}=570 \mathrm{~nm}$ and the absorbance difference $\left(A_{495}-A_{570}\right)$ was plotted against the concentration of the corresponding carbohydrate. The quantity of surface-linked carbohydrate was determined with $60 \mu \mathrm{L}$ of the corresponding ND particles solution in water $\left(0.8 \mathrm{mg} \mathrm{mL}^{-1}\right)$, which was treated with phenol/ $\mathrm{H}_{2} \mathrm{SO}_{4}$ following the same protocol described above. ND-OH particles were treated in the same manner and used as a blank sample.

\subsection{Lectin binding assay}

The binding affinity of the different glycol-NDs was evaluated using FITC-labeled Concanavalin A (Con A), FITC-labeled Arachis hypogaea (PNA) and FITC-labeled Lens culinaris (LENS). The glyco-NDs $\left(1 \mathrm{mg} \mathrm{mL}^{-1}, 100 \mu \mathrm{L}\right)$ suspended in Tris buffer solution ( $\mathrm{pH}$ 7.4 containing $\mathrm{Mg}^{2+}, \mathrm{Ca}^{2+}, \mathrm{NaCl}$ ) were mixed with $300 \mu \mathrm{L}$ solutions of the different lectins (1 $\mathrm{mg} \mathrm{mL}^{-1}$ ) in Tris buffer solution and the reaction mixture left under gentle shaking for $1 \mathrm{~h}$. In order to remove nonreacted lectins, three additional washing/centrifugation cycles at 10000 rpm with Tris buffer were carried out. Fluorescent measurements were performed using an excitation wavelength of $485 \mathrm{~nm}$ and an emission wavelength of $520 \mathrm{~nm}$ (GFP filter).

\subsection{Fluorescence-based agglutination assay}

To $0.7 \mathrm{~mL}$ of E. coli UTI89 bacteria $\left(1 \times 10^{8} \mathrm{cfu} \mathrm{ml}^{-1}\right)$ expressing the TurboFP635 protein (Katushka) were added $0.3 \mathrm{~mL}$ of ND-mannan or ND-mannose particles solution $\left(1 \mathrm{mg} \mathrm{mL}^{-1}\right)$ and kept for $4 \mathrm{~h}$ at $4{ }^{\circ} \mathrm{C}$. Thereafter the solutions were dropped onto microscopic slides, covered with cover slips and sealed. Fluorescence images were recorded at an excitation wavelength $\lambda_{\mathrm{ex}}=580 \mathrm{~nm}$ and an emission wavelength $\lambda_{\mathrm{em}}=635 \mathrm{~nm}$.

\subsection{Instrumentation}

FTIR spectra in transmission mode were recorded using a ThermoScientific FTIR instrument (Nicolet 8700) with a resolution of $4 \mathrm{~cm}^{-1}$. Dried ND powder $(1 \mathrm{mg})$ was mixed with $\mathrm{KBr}$ powder $(100 \mathrm{mg})$ in an agate mortar. The mixture was pressed into a pellet under 10 tons load for 2-4 min, and the spectrum was recorded immediately. Sixteen accumulative scans were collected. The signal from a pure $\mathrm{KBr}$ pellet was subtracted as a background.

X-ray photoelectron spectroscopy (XPS) experiments were performed in a PHl 5000 VersaProbe - Scanning ESCA Microprobe (ULVAC-PHI, Japan/USA) instrument at a base pressure below $5 \times 10^{-9}$ mbar. Monochromatic $\mathrm{Al}_{\mathrm{K} \alpha}$ radiation was used and the $\mathrm{X}$-ray beam, focused to a diameter of $100 \mu \mathrm{m}$, was scanned on a $250 \times 250 \mu \mathrm{m}$ surface, at an operating power 12

DOI: 10.1002/cnma.201500229 - Journal: ChemNanoMa- Post-print 
of $25 \mathrm{~W}(15 \mathrm{kV})$. Photoelectron survey spectra were acquired using a hemispherical analyzer at pass energy of $117.4 \mathrm{eV}$ with a $0.4 \mathrm{eV}$ energy step. Core-level spectra were acquired at pass energy of $23.5 \mathrm{eV}$ with a $0.1 \mathrm{eV}$ energy step. All spectra were acquired at $90^{\circ}$ between $\mathrm{X}$-ray source and analyzer and with the use of low energy electrons and low energy argon ions for charge neutralization. After subtraction of the Shirley-type background, the core-level spectra were decomposed into their components with mixed Gaussian-Lorentzian (30:70) shape lines using the CasaXPS software. Quantification calculations were performed using sensitivity factors supplied by PHI.

Transmission electron microscopy (TEM) images were recorded on a JEOL JEM-2100 electron microscope operated at an accelerating voltage of $200 \mathrm{kV}$.

Absorption spectra were recorded using a Jasco V-570 UV/VIS/NIR Spectrophotometer from Jasco Int. Co. Ltd., Tokyo, Japan.

ND suspensions $\left(20 \mu \mathrm{g} \mathrm{mL}^{-1}\right)$ in water were sonicated. The particle size of the ND suspensions was measured at $25^{\circ} \mathrm{C}$ using a Zetasizer Nano ZS (Malvern Instruments S.A., Worcestershire, U.K.) in $173^{\circ}$ scattering geometry and the zeta potential was measured using the electrophoretic mode.

Fluorescent measurements were carried out using PHERAstar FS microplate reader using an excitation wavelength of 485 and an emission wavelength of $520 \mathrm{~nm}$.

Confocal fluorescence images were acquired by using a confocal microscope (Leica TCS SP5X, Mannheim, Germany) with a $63 \times$ objective (Leica Plan Apo, NA=1.2, water immersion). The photomultiplier tubes integrated to the SP5X were used to detect the fluorescence coming from the turboFP635 (Katushka) fluorescent protein expressed in the bacteria $\left(\lambda_{\mathrm{ex}}=580 \mathrm{~nm} ; \lambda_{\mathrm{em}}=635 \mathrm{~nm}\right)$.

\section{Acknowledgements}

Financial support from the Centre National de la Recherche Scientifique (CNRS), the University Lille, the Nord Pas-de-Calais region and the Institut Universitaire de France (IUF) are acknowledged. We also thank the European Union through financial support (FP7PEOPLE-2010-IRSES) action "Photorelease", grant number 269009 and H2020-MSCE-RISE2015 (PANG, Nr. 690836).

\section{References}

1. Barras, F. A. Martin, O. Bande, J. S. Baumann, J.-M. Ghigo, R. Boukherroub, C. Beloin, A. Siriwardena, S. Szunerits, Nanoscale 2013, 5, 2307.

2. M. Khanal, A. Barras, T. Vausselin, L. Fénéant, R. Boukherroub, A. Siriwardena, J. Dubuisson, S. Szunerits, Nanoscale 2015, 7, 1392-1402.

3. M. Marradi, F. Chiodo, I. Garcia, S. Penades, Chem. Soc. Rev. 2013, 42, 4728-4745.

4. M. Hartmann, P. Betz, Y. Sun, S. H. Gorb, T. K. Lindhorst, A. Krueger, Chem. Eur. J. $2012,18,6485$.

5. J. M. Tam, M. K. Mansour, N. S. Khan, N. C. Yoder, J. M. Vyas, Integr. Biol. 2012, 4, 220. 
6. Fessele, S. Wachtler, V. Chandrasekaran, C. Stiller, T. K. Lindhorst, A. Kruefer, Eur. J. Org. Chem. 2015, 5519-5525.

7. N. Sharon, H. Lis, Glycobiology 2004, 14, 53R.

8. S. Cecioni, V. Oerthel, J. Iehl, M. Hoiller, D. Goyard, J.-P. Praly, J. F. Imberty, J.-F. Nierengarten, S. Vidal, Chem. Eur. J. 2011, 17, 3252.

9. M. Almant, V. Moreau, J. Kovernsky, J. Bouckaert, S. G. Gouin, Chem. Eur. J. 2011, $17,10029$.

10. S. Brument, A. Sivignon, N. Moreau, G. Roos, Y. Gueradel, T. Chalopin, D. Deniaud, R. Bilyy, A. Darfeille-Michaud, J. Bouckaert, S. G. Gouin, J. Med. Chem. 2013, 56, 5395-5406.

11. N. C. Reichardt, M. Martin-Lomas, S. Penades, Chem. Soc. Rev. 2013, 42, 4358.

12. M. Khanal, F. Larsonneur, V. Raks, A. Barras, J.-S. Baumann, F. A. Martin, R. Boukherroub, J.-M. Ghigo, C. Ortiz Mettet, V. Zaitsev, J. M. Garcia Fernances, C. Beloin, A. Siriwardena, S. Szunerits, Nanoscale 2015, 7, 2325-2335.

13. M. Durka, K. Buffet, J. Iehl, M. Holler, D. Hazelard, T. M. Barragan, C. O. Mellet, J.F. Nierengarten, Chem. Commun. 2011, 47, 1321.

14. P. Compain, C. Decroocq, I. Ihel, M. Holler, D. Hazelard, T. M. Barragan, C. O. Mellet, J.-F. Nierengarten, Angew. Chem. Int. Ed. 2010, 49, 5753.

15. M. Khanal, V. Raks, R. Issa, V. Chernyshenko, A. Barras, J. M. Garcia Fernandes, A. Siriwardena, I. Cooper, P. Cragg, L. I. Mikhalovska, V. Zaitsev, R. Boukherroub, S. Szunerits, Part. Part. Syst. Charact. 2015, 32, 822-830.

16. Barras, J. Lyskawa, S. Szunerits, P. Woisel, R. Boukherroub, Langmuir 2011, 27, 12451-12457.

17. V. N. Mochalin, O. A. Shenderova, D. Ho, Y. Gogotsi, Nat. Nanotechnol. 2012, 7, $11-$ 23.

18. Krueger, Chem. Eur. J. 2008, 14, 1382-1390.

19. J. Slegerova, M. Hajek, I. Rehor, F. Sedlak, J. Stursa, M. Hruby, P. Cigler, Nanoscale 2015, 7, 415.

20. L. Zhao, Y.-H. Xu, H. Qin, S. Abe, T. Akasaka, T. Chano, F. Watari, T. Kimura, N. Komatsu, X. Chen, Adv. Funct. Mater. 2014, 24, 5348-5357.

21. Rehor, J. Slegerova, J. J. Kucka, V. Proks, V. Petrakova, M.-P. Adam, F. Treussart, S. Turner, S. Bals, P. Sacha, M. Ledvina, A. M. Wen, N. F. Steinmetz, P. Cigler, Small 2014, 10, 1106.

22. L. Marcon, F. Riquet, D. Vicogne, S. Szunerits, J. F. Bodart, R. Boukherroub, J. Mater. Chem. 2010, 20, 8064-8069.

23. M. Schrand, H. Huang, C. Carlson, J. J. Schlager, E. Osawa, S. M. Hussain, L. Dai, J. Phys. Chem. B 2007, 111, 2-7.

24. V. Vaijayanthimala, S. V. Kimb, A. Yen, N. Tsai, D. Ho, H.-C. d. Chang, O. Shenderova, Expert Opin. Drug Delivery 2015, 12, 735.

25. M. Khanal, T. Vausselin, A. Barras, O. Bande, K. Turcheniuk, M. Benazza, V. Zaitsev, C. M. Teodurescu, R. Boukherroub, A. Siriwardena, J. Dubuisson, S. Szunerits, ACS Appl. Mater. Interfaces 2013, 5, 12488-12498.

26. R. Martín, M. Álvaro, J. R. Herance, H. García, ACS Nano 2010, 4, 65-74.

27. M. Khanal, V. Turcheniuk, A. Barras, R. Rosay, O. Bande, A. Siriwardena, V. Zaitsev, G.-H. Pan, R. Boukherroub, S. Szunerits, Langmuir 2015, 31, 3926-3933.

28. X. Wang, O. Ramstrom, M. Yan, J. Mater. Chem. 2009, 19, 8944.

29. X. Wang, E. Matei, L. Deng, O. Ramstrom, M. Gronenborn, M. Yan, Chem. Commun. 2011, 47, 8620-8622.

30. X. Wang, O. Ramstrom, M. Yan, Chem. Commun. 2011, 47, 4261-4263. 
31. N. Maalouli, A. Barras, A. Siriwardena, R. Boukherroub, S. Szunerits, Analyst 2013, $138,805-812$.

32. M. Hartmann, T. K. Linhorst, Eur. J. Org. Chem. 2011, 2011, 3583-3609.

33. X. Yan, A. Sivignon, P. Alcouffe, B. Burdin, S. Favre-Bonté, R. Bilyy, N. Barnich, E. Fleury, E. Ganachaud, J. Bernard, Chem. Commun. 2015, 51, 13193.

34. K. Turcheniuk, C.-H. Hage, J. Spadavecchia, A. Y. Serrano, I. Larroulet, A. Pesquera, A. Zurutuza, M. G. Pisfil, L. Heliot, J. Bouckaert, R. Boukherroub, S. Szunerits, J. Mater. Chem. B 2015, 3, 375-386.

35. H. Vu-Quang, M. Muthiah, Y.-K. Kim, C.-S. Cho, R. Namgung, W. J. Kim, J. H. Rhee, S. H. Kang, S. Y. Jun, Y.-J. Choi, Y. T. Jeong, I.-Y. Park, Carbohydr. Polym. 2012, 88, 780-788. 